\title{
AS TRAJETÓRIAS DE DIVERSIFICAÇÃO E DIFERENCIAÇÃO DO COMÉRCIO EXTERIOR BRASILEIRO ENTRE 2000 E 2012
}

\author{
Jefferson Ricardo Galetti ${ }^{1}$
}

Carlos Frederico Rocha ${ }^{2}$

\section{Área ABEIN: Área 2 - Comércio Internacional e cadeias de valor}

\section{Resumo}

Este trabalho investiga o processo de diversificação e diferenciação das exportações brasileiras entre 2000 e 2012 sob a ótica das trajetórias de desenvolvimento de Saviotti e Pyka (2012). O objetivo deste estudo é identificar quais os setores que, dentro de um contexto favorável ao comércio internacional, conseguiram se integrar às trajetórias associadas à ampliação da elasticidade-renda da demanda. A partir da literatura sobre desenvolvimento econômico, as diferentes elasticidades-renda da demanda foram identificadas como uma das forças que interagem, juntamente com a difusão diferenciada do progresso técnico, para a ocorrência da mudança estrutural que caracteriza o desenvolvimento econômico. Um cenário de crescimento do comércio exterior que impeça o surgimento de restrições derivadas do balanço de pagamentos - como o observado no Brasil durante o período abordado - pode favorecer os processos de diversificação e diferenciação. Utilizando índices Hirschman-Herfindahl e do Valor Unitário para medir a diversificação e a diferenciação das exportações brasileiras no período, encontramos que os setores baseados, direta ou indiretamente, em recursos naturais foram os que apresentaram maior diversificação e diferenciação no período. Além disso, as importações brasileiras parecem ainda possuir uma diferenciação e qualidade maiores que as exportações. O estudo contribui para a compreensão do desempenho do comércio sob a ótica da força motriz do desenvolvimento associada à demanda ainda pouco explorada nos estudos sobre o comércio exterior brasileiro.

Palavras-Chave: Mudança estrutural; Diversificação; Diferenciação; Comércio Internacional.

\begin{abstract}
This work investigates the process of diversification and differentiation of Brazilian exports between 2000 and 2012 from the perspective of trajectories of development (Saviotti and Pyka, 2012). The objective of this study is to identify which sectors managed to integrate the trajectories associated with the expansion of the income elasticity of demand in a context of favorable environment for international trade. From the literature on economic development, the different income-elasticities of demand have been identified as one of the forces that interact with the differential diffusion of technical progress for the occurrence of structural change in economic development. The growth of foreign trade that prevents balance of payments restrictions - as observed in Brazil during the period covered - may enhance the diversification and differentiation processes. Using Hirschman-Herfindahl index and the Unit Value to measure the diversification and differentiation of Brazilian exports in the period, we find that sectors based directly or indirectly in natural resources were those with greater diversification and differentiation in the period. In addition, Brazilian imports still seem to have a greater differentiation and quality than exports have. The study contributes to the understanding of the performance of international trade from the perspective of the demand side driving force associated with development that is still little explored in studies of Brazilian foreign trade.
\end{abstract}

Keywords: Structural change; Diversification; Differentiation; International Trade.

JEL: F14; O10

\footnotetext{
${ }^{1}$ Doutorando em Economia da Indústria e da Tecnologia. Programa de Pós-Graduação em Economia. Universidade Federal do Rio de Janeiro (UFRJ). Email: jeffersongaletti@gmail.com

${ }^{2}$ Professor Associado do Instituto de Economia da Universidade Federal do Rio de Janeiro. Email: Fred@ie.ufrj.br
} 


\section{Introdução}

O desenvolvimento econômico é compreendido como o processo de mudança estrutural no qual os setores econômicos apresentam crescimento distinto entre si, resultando em alterações na composição dos agregados econômicos e moldando a evolução da economia no longo prazo. É um processo de crescimento não equilibrado (Hirschman, 1960) no qual duas forças interagem continuamente. A primeira refere-se aos efeitos diferenciados do progresso técnico que resulta em crescimento desigual da eficiência produtiva entre os diversos setores, enquanto a segunda diz respeito aos diferentes graus de elasticidade da demanda (Krüger, 2008). Como conseqüência da interação dessas forças a produtividade setorial e total aumenta e a diversificação da produção e a diferenciação dos produtos e serviços se estabelecem, mantendo a sociedade em uma rota de desenvolvimento no longo prazo.

A visão de que o comércio tem impacto cumulativo e circular sobre a economia deriva da análise de Kaldor (1970), onde crescimento do produto é influenciado pelo aumento das exportações, que dependem da renda externa e também da competitividade da indústria local. Por sua vez, a competitividade depende parcialmente da produtividade, que é determinada com o crescimento do produto. Portanto, há um canal de transmissão do comércio para o crescimento, considerando que o aumento da demanda pelos produtos exportados também representa aumento da demanda pela produção doméstica. A expansão das exportações pode gerar um processo de especialização nos bens e serviços tradeables, ampliar capacitações e trazer ganhos de learning-by-doing. O crescimento das vendas externas permite a exploração das economias de escala e a superação de problemas de restrição cambial e assim, possibilita as importações de bens de consumo e insumos para a produção doméstica, aumentando a competitividade desta última (Gilles e Williams, 2000).

Saviotti e Pyka (2012) formalizaram a interação das duas forças motrizes em três trajetórias estilizadas que explicam o desenvolvimento econômico de longo prazo. Aqui, vamos utilizar as duas últimas trajetórias em um recorte parcial, que exclui a produção e considera apenas o comércio exterior. As três trajetórias originalmente são:

1. A eficiência do processo de produção aumenta ao longo do tempo, de modo que menos insumos sejam necessários para a produção do mesmo nível de bens e serviços.

2. A variedade produtiva também cresce com o tempo. A diversificação é resultado da emergência de novos setores, definidos como um conjunto de firmas produzindo um produto comum, porém diferenciado.

3. A qualidade dos bens e serviços é crescente ao longo do tempo e resulta em diferenciação interna aos setores.

A primeira trajetória refere-se à primeira força motriz da mudança estrutural que altera a produtividade de modo distinto entre os setores e possibilita a existência de economias de escala, a ampliação da eficiência no uso dos recursos e maior competitividade. Já a segunda e terceira trajetórias caracterizam a elasticidade-renda da demanda, indicando que a procura por alguns produtos é mais elevada que a de outros e possibilita aos setores que os ofertam desfrutarem de uma maior taxa de crescimento das vendas.

A interação entre as duas forças motrizes do desenvolvimento econômico não se restringe apenas à esfera produtiva de uma economia, mas também pode ser analisada sob a ótica do comércio exterior. Alguns estudos já perscrutaram a relação entre os exportadores brasileiros e a eficiência produtiva e em geral encontraram resultados que sugerem que as firmas exportadoras têm produtividade maior do que as não exportadoras. Arbache (2005) encontrou resultados que sugerem que as exportações têm efeito maior sobre a produtividade das empresas que exportam produtos padronizados do que sobre as firmas que diferenciam produtos. Para Gomes e Ellery (2007) as empresas que exportam para o Mercosul - com pauta exportadora com produtos mais sofisticados - são menos produtivas que as exportadoras para outros mercados; e Hidalgo e Mata (2009) não encontraram diferenças de crescimento da produtividade 
das empresas exportadoras e não-exportadoras. Já Hiratuka e Cunha (2011) abordaram a qualidade e diferenciação das exportações brasileiras, mas o fazem em comparação com as exportações da China, enfatizando o acirramento da concorrência e mostrando que, apesar do aumento do market share das exportações chinesas, nos segmentos de alta qualidade, o Brasil ainda tem qualidade superior. Além de Hiratuka e Cunha (2011), são poucos os trabalhos sobre as exportações brasileiras relacionadas à segunda força motriz do desenvolvimento - elasticidade-renda da demanda. Este artigo busca contribuir para o preenchimento desta lacuna na literatura e vai tratar da evolução das trajetórias de diversificação e diferenciação no comércio exterior brasileiro nos anos 2000.

O objetivo deste artigo é identificar e analisar qual o desempenho do comércio exterior brasileiro entre 2000 e 2012 sob a ótica da segunda e terceira trajetórias de desenvolvimento de Saviotti e Pyka (2012). Em outras palavras, o artigo procura responder se dentro de um contexto favorável ao comércio exterior brasileiro os setores exportadores conseguiram ampliar a diversificação e a diferenciação da pauta exportadora e se integrar às trajetórias associadas à ampliação da elasticidade-renda da demanda.

Este artigo contém mais três seções além desta introdução e das conclusões. A próxima seção busca fazer uma revisão da literatura considerando a interação entre as trajetórias, a rota de desenvolvimento e o papel do comércio exterior neste processo. A terceira seção apresenta a metodologia e os dados utilizados para a mensuração, identificação e análise dos setores que se integraram às trajetórias de diversificação e diferenciação. E, finalmente, a quarta seção apresenta os resultados obtidos nesta pesquisa e discute brevemente quais os fatores que dotam um país com capacitações apropriadas para diversificar e diferenciar suas exportações.

\section{A interação das trajetórias de desenvolvimento e o comércio exterior}

Saviotti e Pyka (2012) afirmam que a interação entre as três trajetórias de desenvolvimento resulta em uma transformação estrutural marcada pelo aumento da diversificação e diferenciação da economia. Apenas o aumento da eficiência produtiva e o crescimento da produtividade (Trajetória 1) de um conjunto estável de bens levariam a um desequilíbrio entre o aumento da produção e o crescimento da demanda. Nesse caso, o processo de crescimento econômico seria interrompido pela saturação da demanda pelo conjunto estável de bens produzidos. Aoki e Yoshikawa (2002) chamaram a atenção para um "fato estilizado" retirado de Rostow (1978) sobre o ciclo de vida de um produto, que teria uma curva logística, em forma de "S". A produção de um produto individual ou mesmo de uma indústria tende a declinar por que a demanda por esse produto ou indústria aumenta rapidamente nos primeiros estágios, mas a partir de determinado momento necessariamente começa a diminuir.

A superação do problema da saturação da demanda é o crescimento da variedade produtiva (Trajetória 2), com o surgimento de novos setores e sobreposição de novos produtos com o objetivo de manter elevada a elasticidade-renda da demanda. Simultaneamente à criação de novos setores e novos produtos ocorre o aumento da qualidade e a diferenciação interna aos setores (Trajetória 3), com novas safras de produtos, com mais funções e serviços disponíveis ao consumidor. A mudança estrutural que emerge com os novos setores e produtos e com sua diferenciação interna são o ponto fundamental que resulta em expansão do limite superior da demanda - em outras palavras, que amplia a elasticidade-renda - pelos produtos de um país.

O processo de desenvolvimento econômico somente pode ocorrer com a presença e interação dessas três trajetórias. Inicialmente, o crescimento da eficiência produtiva concorre para reduzir os custos de produção e ampliar a renda real na economia. Deste acréscimo da renda, parte é destinada aos trabalhadores na forma de salários e parte é direcionada às empresas na forma de lucros, para ser utilizada em consumo e investimento, respectivamente. O excedente gerado pelo aumento da eficiência produtiva provê recursos para o financiamento de atividades empresariais de busca tecnológica e de investimentos requeridos para a criação de novas atividades econômicas e novos bens e serviços. 
A renda apropriada pelos trabalhadores das atividades existentes e dos novos investimentos é responsável pela ampliação da demanda que se estende a esses novos produtos, confirmando e chancelando os esforços tecnológicos e os investimentos destinados à diversificação produtiva. A expansão da demanda não segue uma relação linear com a renda disponível, e apenas após a ultrapassagem de um determinado limiar, os consumidores destinarão parte de sua renda para além dos bens de necessidade, de modo que a participação destes no total da renda diminua- relação conhecida como Lei de Engel. A transição da demanda por bens de necessidade básica para uma cesta composta por mais variedades possibilita a consolidação de uma estrutura produtiva diversificada originada do crescimento da eficiência produtiva.

O crescimento da renda real também permite a emergência de diferenciações intrassetoriais, quando bens e serviços similares a ponto de serem classificados dentro de uma mesma classe são produzidos utilizando composições diferentes de insumos (Schott, 2004). As diferenciações exigem um esforço de inovação que busca o refinamento de características existentes e a incorporação de novas funções aos produtos e ao mesmo tempo, tende a elevar a elasticidade-renda de demanda e a manter o ritmo de desenvolvimento. Exemplos de diferenciação são o ambiente agradável e o status que um restaurante adiciona à satisfação de uma necessidade básica como a alimentação e os aplicativos e novas funções dos smartphones que o diferenciam dos primeiros telefones móveis. É dessa maneira que a crescente diferenciação e aumento da qualidade (trajetória 3) associada ao surgimento de novos setores (trajetória 2) pode compensar a limitação imposta pela demanda aos setores existentes na criação de renda e emprego e caracteriza o desenvolvimento econômico como um processo de transformação que gera mudanças qualitativas e quantitativas no sistema produtivo (Saviotti e Pyka, 2012).

Especialmente nos casos dos países em desenvolvimento, as exportações podem ser o fator que coloca em marcha esse mecanismo dinâmico de desenvolvimento econômico. Em certa medida, a estrutura de exportações reflete a estrutura produtiva de um país. Ou seja, exportações competitivas indicam que o processo produtivo desses produtos está mais próximo da fronteira tecnológica internacional. Gilles e Williams (2000) fizeram uma revisão da literatura da teoria de Export led growth e sintetizaram as razões pelas quais as exportações contribuem decisivamente para o desenvolvimento econômico. A primeira razão também se refere à inter-relação existente entre as estruturas comercial e produtiva, enfatizando que o aumento da demanda pelos bens nacionais no mercado internacional significa expansão da demanda pela produção interna e, portanto, servem para aumentar o produto real de uma economia. Além disso, a expansão das exportações pode promover uma especialização nos bens "exportáveis", aumentando a capacitação e a produtividade dos setores exportadores. A terceira razão refere-se ao alívio à restrição cambial, facilitando a importação de insumos e expandindo a eficiência da produção doméstica. A quarta razão diz respeito à utilização das economias de escala que as exportações podem possibilitar ao ampliar o tamanho do mercado. E finalmente as exportações podem dotar um país com conhecimento necessário para migrar das vendas externas de produtos mais simples para uma cesta de produtos mais complexos e intensivos em tecnologia.

No entanto, para que as exportações sejam parte fundamental do complexo mecanismo de mudança estrutural, os produtos vendidos externamente devem contar com demanda elástica à renda que seja capaz de impulsionar as vendas sem que ocorram perdas nos termos de intercâmbio (Hesse, 2008). Para isso, as exportações devem ser capazes de ampliar a diversificação e diferenciação para se integrarem às duas trajetórias de desenvolvimento associadas a uma maior elasticidade-renda da demanda.

A trajetória de diversificação e a inserção de novos produtos que expandam a elasticidade-renda da demanda da pauta exportadora podem estabilizar os ganhos advindos do comércio exterior, dado que a forte concentração em apenas alguns poucos produtos pode tornar instáveis as receitas de exportação, especialmente se os produtos forem commodities, sejam elas agropecuárias, minerais ou industriais. A volatilidade da balança comercial pode desencorajar investimentos, gerar incertezas macroeconômicas e prejudicar o crescimento econômico (Hesse, 2008). Além disso, a diversificação produtiva por um grupo inicial de exportadores pode gerar um processo de "descobrimento" de demanda externa por parte de 
outras empresas imitadoras e aumentar o impacto do comércio sobre o crescimento econômico (Vettas, 2000 apud Hesse, 2008).

Hesse (2008) encontrou evidências de um efeito positivo da diversificação das exportações sobre a renda per capita de um país. Os benefícios da diversificação da pauta de exportação foram maiores para os países em desenvolvimento em relação aos países desenvolvidos, que mostraram uma maior especialização de suas exportações. Resultados similares foram encontrados por Funke e Ruhwedel (2001). Eles mostraram que uma maior variedade de produtos exportados teve impacto positivo sobre o PIB, sobre o crescimento da produtividade total dos fatores e sobre a renda per capita em 18 países da OCDE entre 1989 e 1996. Hummels e Klenow (2005) afirmaram que a maior parte do aumento das exportações ocorreu com o aumento das margens extensivas, ou seja, com o aumento do número de produtos exportados. Esses resultados são compatíveis com os do estudo de Imbs e Wacziarg (2003). Estes autores encontraram evidências de que um país de renda baixa diversifica sua estrutura produtiva inicialmente e somente a partir de um determinado nível de renda inicia um movimento de especialização da produção.

Saviotti e Frenken (2008) resumem os efeitos da diversificação exportadora sobre a taxa de crescimento do PIB per capita: países que apresentaram melhor desempenho econômico foram aqueles que mais ampliaram a diversificação de suas exportações; o efeito positivo da diversificação foi maior quanto maior a distância inicial que os países se encontravam de uma “fronteira” de diversificação das exportações - trata-se, portanto, de um processo convergente; os países mais ricos em recursos naturais apresentaram convergência mais lenta em relação à "fronteira”; as maiores taxas de diversificação foram dos países com melhor desempenho econômico: Coreia, Taiwan, China e Malásia; e finalmente, apesar da diversificação, a pauta das exportações dos que se aproximavam da "fronteira" tornava-se mais similar a dos demais países.

Já a terceira trajetória de desenvolvimento registra o processo de aumento da qualidade e da diferenciação dos bens e serviços comercializados no mercado internacional à medida que a estrutura econômica se torna mais eficiente e mais diversificada. A elasticidade da demanda com o aumento da renda é ampliada com a diversificação e com a diferenciação entre produtos classificados dentro de uma mesma categoria da pauta exportadora.

No entanto, nem todos os produtos exportados possuem a mesma possibilidade de sofrerem diferenciações e aumentos de qualidade contínuos. Alguns produtos possuem uma "escada de qualidade" ou "quality ladder” mais longa do que outros (Grossman e Helpman, 1991). De acordo com Saviotti e Metcalfe (1984), os bens e serviços possuem dois conjuntos de características, que combinados, os descrevem. Os usuários estão interessados nos serviços que o produto pode oferecer - conjunto de serviços - enquanto as empresas devem produzi-lo com um determinado conjunto de características técnicas, assegurando a incorporação dos serviços demandados. Portanto, os conjuntos de características técnicas e de serviços que um produto possui definem a extensão de sua "escada de qualidade". Guimarães (1981) fornece alguns exemplos que nos ajudam a entender como certos produtos podem sofrer aumentos de diferenciação e qualidade em relação aos demais. As oportunidades de diferenciação serão maiores quando os consumidores e usuários puderem comparar os diversos critérios dos dois conjuntos que diferenciam os produtos novos dos velhos. E as oportunidades de diferenciação serão maiores quanto mais critérios cada conjunto possuir. Segundo Guimarães (1981) um produto unidimensional possui apenas uma característica relevante para a escolha do consumidor, como o carvão que é avaliado normalmente apenas pelo seu poder calorífico. Já o automóvel, por exemplo, é multidimensional e exige uma maior capacidade do consumidor em avaliar cada item disponível no conjunto de serviços. Qual a vantagem de um veículo em relação aos seus concorrentes na comparação do consumo de combustível, da potência do motor, do conforto e do status que oferece? Da mesma forma, do lado da oferta, os produtos multidimensionais, normalmente possibilitam mais oportunidades para a aplicação dos avanços de conhecimentos científicos e tecnológicos em seu conjunto de características técnicas, além de possibilitar diferentes estratégias competitivas. 
Dessa forma, a especialização em alguns tipos de produtos pode ter diferentes impactos sobre o desenvolvimento econômico de acordo com a extensão de suas “escadas de qualidade”. Para Hwang (2006 apud Lederman e Maloney, 2012) os países com escadas de qualidade mais curtas possuem maiores limitações ao seu potencial de crescimento. Nesse caso, os países em desenvolvimento especializados em commodities naturais- que ou são unidimensionais ou possuem poucos critérios para avaliação - teriam menos oportunidades de diferenciação e apresentariam desvantagens nesse processo.

No comércio internacional, Schott (2004) observou que o número de produtos importados pelos Estados Unidos de países ricos ou pobres exclusivamente tem diminuído ao longo do tempo. Para o autor isso é uma evidência de que o comércio se tornou mais do que intraindustrial, tornou-se um comércio de distintas qualidades, de produtos diferenciados. De acordo com seus cálculos, entre 1972 e 1994, o percentual de produtos originados simultaneamente em três classificações de países, os de baixa, média e alta rendas aumentou de $48 \%$ para $74 \%$. Se cada vez mais o comércio internacional não se distingue por produtos exportados por países ricos e pobres, o que distingue as pautas de exportação entre esses grupos de países?

Schott (2004) e Hummels e Klenow (2005) encontraram evidências de que o valor unitário das exportações (razão entre o valor das exportações e o seu peso) aumenta de acordo com o PIB per capita do país exportador. Essa relação sugere que o processo dinâmico envolvido na diferenciação de produtos exportados pode oferecer um caminho para acelerar o desenvolvimento econômico, que depende do tamanho das "escadas de qualidade" que cada produto pode escalar.

Henn, Papageorgiou e Spatafora (2015) refinaram um pouco essa afirmação e mostraram que o incremento de qualidade das exportações ocorre mais rapidamente nos estágios iniciais de desenvolvimento e se completa quando o país alcança uma renda considerada "média-alta”. De um modo geral, a qualidade é associada positivamente com a renda: o incremento da qualidade aumenta mais rápido até o PIB per capita atingir um nível de $\$ 10.000$ e então a convergência de qualidade continua crescendo a taxas decrescentes e estabiliza quando o país atinge a renda de $\$ 20.000$. Portanto, o nível de qualidade de um produto individual converge ao longo do tempo, porém a taxa de convergência é maior quando o nível inicial de qualidade do produto é menor. Por exemplo, as exportações de recursos naturais da América Latina possuem “escada” curta e já se encontram próximos da "fronteira” de qualidade, o que pode explicar por que essa região apresenta uma taxa de crescimento menor. Em um elevado nível de qualidade, o incremento da diferenciação do produto é mais acessível aos países desenvolvidos em relação aos países em desenvolvimento, sugerindo que aqueles possuem mais canais de spillover e conseguem capturar maiores benefícios de seu conjunto de conhecimentos.

Apesar da convergência que esses estudos encontraram no nível de qualidade dos produtos exportados, ainda existe grande heterogeneidade entre países e regiões. Lederman e Maloney (2012) resumem os resultados de trabalho anterior de Krishna e Maloney (2011), que examinaram o processo de mudança de qualidade e diferenciação ao longo do tempo. Apesar de também encontrarem convergência entre produtos, descobriram que o mesmo não se aplica às regiões produtoras. Os países da OCDE têm a maior taxa de crescimento da qualidade, e dado o maior nível relativo de qualidade que possuem, pode-se afirmar que a qualidade é divergente entre as regiões. Na análise de regressão, ao se controlar por produtos os resultados mantiveram a divergência regional, mas reduziram a distância em relação à OCDE. Isso sugere que os tipos de produtos que os países exportam têm influência sobre seu valor unitário. Ao se controlar pela cesta de bens exportados, existe um efeito regional significante: caso os mesmos produtos fossem fabricados pelos países da OCDE e por países em desenvolvimento, os primeiros teriam taxa de crescimento da qualidade maior, mesmo com sua maior proximidade da fronteira.

Para Lederman e Maloney (2012), o efeito regional em favor dos países desenvolvidos em aumentar mais rápido a diferenciação de seus produtos domina o efeito de convergência dentro das mesmas categorias de produtos. Ou seja, mesmo se a América Latina e Caribe exportassem a mesma cesta de produtos da OCDE seu desempenho em aumentar a qualidade seria inferior. O que nos leva à importante observação 
feita por Saviotti e Frenken (2008): a variedade e qualidade das exportações não são os fatores determinantes do desenvolvimento econômico como a tecnologia é, por exemplo. Os processos de diversificação e diferenciação associados à expansão da elasticidade da demanda por seus produtos dependem de muitos outros fatores, em concordância com a complexidade e multidimensionalidade do desenvolvimento econômico. Portanto, a integração à segunda e terceira trajetórias de desenvolvimento depende de atividades de busca por inovações, produção de tecnologias, geração e acumulação de conhecimentos em pessoas e empresas, sejam individualmente ou conectados em rede, depende de aumento das capacitações tecnológicas dos diversos setores que compõem a economia, de um modo geral, e dos exportadores, de acordo com a ótica adotada neste trabalho.

A próxima seção apresenta a metodologia e os dados utilizados para identificar quais setores exportadores do Brasil conseguiram ampliar a diversificação e a diferenciação de produtos e assim contribuir para o processo de desenvolvimento econômico.

\section{Dados e metodologia}

As informações sobre as exportações e importações brasileiras do período 2000 a 2012 foram obtidas por meio do sistema AliceWeb disponibilizado pela Secex/MDIC. Foram coletados os valores de exportação em US\$ e o peso em quilogramas das categorias de produtos da máxima desagregação disponível, agrupados em oito dígitos de acordo com o código de Nomenclatura Comum do Mercosul (NCM). O Grupo de Indústria e Competitividade da Universidade Federal do Rio de Janeiro (GIC/UFRJ) realizou um trabalho de correspondência entre os códigos de oito dígitos NCM e os códigos de três dígitos dos grupos CNAE 2.0. Além da máxima desagregação em termos de produtos, também foram mantidas todas as transações por NCM para cada país destino das exportações nacionais.

Para a identificação e análise da diversificação do comércio exterior brasileiro a partir dos anos 2000, foi utilizado o índice de Hirschman-Herfindahl. Na verdade, este índice mede o nível de concentração das exportações e não propriamente a diversificação. No entanto, consideramos que a ocorrência de uma desconcentração medida pelo índice seria equivalente a ocorrência de diversificação. Desconcentração e diversificação possuem alguma similaridade em suas definições, porém, não totalmente. Diversificação das exportações significa que os exportadores foram capazes de introduzir novos produtos na cesta que vendem para o exterior. Porém, não existe um nível de desagregação tão alto a ponto de registrar novos produtos que foram acrescentados na pauta de exportação. Já a desconcentração das exportações significa que os valores exportados estão mais igualmente distribuídos entre as categorias de produtos existentes. Dessa forma, vamos considerar que aumentos das exportações registradas nas categorias da Nomenclatura Comum do Mercosul (NCM) mais relevantes ampliam a concentração e uma melhor distribuição das exportações entre os códigos NCM representa uma diversificação da pauta exportadora.

O índice de Hirschman-Herfindahl ${ }^{3}$ setorial é definido por:

$$
H H_{i}=\sum_{i=1}^{n} s_{n c m}^{2} .
$$

Este índice é ponderado pela participação de cada produto NCM a oito dígitos no total, $s_{n c m}$, de modo que as observações maiores tenham um peso maior no cálculo e por isso, quanto maior for o valor de $H H_{i}$ maior será a concentração. Este índice varia entre $\frac{1}{n}$ e 1 , e o limite inferior decresce à medida que o número de observações aumenta e, no limite quando $n \rightarrow \infty$ seu valor é igual a zero. Para que possa ser comparado ao longo do tempo, é possível um ajuste na fórmula para que o índice $H H_{i}$ não dependa do

\footnotetext{
${ }^{3} \mathrm{O}$ índice de Entropia também foi calculado para medir a diversificação setorial das exportações. Como os resultados não foram diferentes dos obtidos pelo índice de Hirschman-Herfindahl, optou-se, devido ao espaço limitado, por apresentar apenas esses últimos neste artigo.
} 
número de observações. Neste caso, seguindo Resende e Boff (2002) o índice $H H^{\prime}{ }_{i}$ tem valores mínimos e máximos entre 0 e 1 :

$$
H H_{i}^{\prime}=1-\left(\frac{1}{n-1}\left[n H H_{i}-1\right]\right)
$$

Um último ajuste é feito ao subtrair o índice $H_{H^{\prime}}{ }_{i}$ da unidade, de modo que quanto maior for o valor calculado do índice, menor é a concentração e, por conseguinte, maior a diversificação das exportações.

A variável a qual se refere a terceira trajetória, o aumento da qualidade e a diferenciação dos produtos exportados, também não pode ser diretamente observada e sua mensuração é um desafio. O valor unitário, a razão entre o valor exportado e o peso das exportações é utilizada como uma proxy da qualidade das exportações. Esta medida também tem suas limitações ao mensurar a qualidade: os valores podem refletir os custos de produção e a estratégia de preços; mudança dos valores ao longo do tempo pode refletir alteração de preços, como as cotações das commodities ou o grau de raridade de um produto, como o diamante e obras de arte como exemplos extremos, e não alterações na qualidade. Além do mais, segundo Henn, Papgeorgiou e Spatafora (2015), qualidade e valor unitário são correlacionados, mas não de uma maneira linear. Uma vez que as exportações de um país atinjam um nível de qualidade próximo de $80 \%$ ou $85 \%$ da fronteira de qualidade, esta variável e o valor unitário não são mais correlacionados. A explicação para isso seria que, aumentos de qualidade para além desse nível não estão relacionados com aumento dos preços, possivelmente por que a maior eficiência na produção teria maior reflexo nos custos de produção.

Apesar das limitações, o valor unitário é uma medida amplamente usada na literatura sobre qualidade das exportações. Schott (2004), Fontagné e Freudenberg (1997), Fontagné, Freudenberg e Gaulier (2005), Henn, Papgeorgiou e Spatafora (2015), entre outros, usam esta medida.

O valor unitário (VU) do grupo CNAE é obtido de acordo com a fórmula:

$$
V U_{i, p}=\frac{V_{i, p}}{Q_{i, p}} .
$$

Onde $i$ é o grupo CNAE e $p$ refere-se ao país identificado como parceiro comercial. Além de agrupar o fluxo comercial de acordo com o grupo CNAE, é importante identificar o mercado de origem das importações ou destino das exportações com o objetivo de comparar os valores unitários entre países dentro de uma mesma classificação CNAE. Essa comparação das exportações e importações de um setor CNAE para diversos países pode mostrar se existe alguma diferenciação de preços (valores unitários) medida pelo coeficiente de variação e, conseqüentemente, de qualidade de acordo com a renda per capitado parceiro comercial, por exemplo. Posteriormente, para obter valores unitários apenas por setores CNAE, $V U_{i}$, serão calculados índices ponderados pela participação dos parceiros comerciais para cada grupo CNAE.

Estes índices de diversificação e diferenciação ainda precisam ser transformados para que forneçam um melhor panorama das exportações brasileiras. Para isso, foram calculados os Índices de Diversificação $\left(I D X_{i}\right)$ e o Índice de Diferenciação e Qualidade das Exportações $\left(I Q X_{i}\right)$.

O $I D X_{i}$ é obtido pela interação entre o índice de diversificação comercial, nesse caso o HH', do setor $i$ e a participação deste setor no total das exportações:

$$
I D X_{i}=H H^{\prime}{ }_{i} \cdot S_{i}
$$

A ponderação do índice $H H^{\prime}{ }_{i}$ pela participação das exportações setoriais (CNAE 2.0 a dois dígitos) no total serve para evitar que um setor com alto grau de diversificação seja identificado como um vetor de desenvolvimento econômico associado à segunda trajetória, mas que na prática não tenha essa influência toda porque não é relevante quando se considera o quadro geral das exportações. Por exemplo, o setor 13 
- Produtos têxteis - apresentou um elevado grau de diversificação com $H H^{\prime}$ médio de 0,95 no período, mas sua participação no total das exportações declinou significativamente, com média inferior a 1\% no período e 0,4\% em 2012. Em contraste, o setor 20 - Produtos químicos - contribuiu mais com a diversificação da pauta de exportações brasileira. Além de seu $H H^{\prime}$ ser elevado, sua participação média no total das exportações foi ao redor de 5,0\%.

O cálculo do $I Q X_{i}$ também considera a participação setorial no total das exportações, mas ainda sofre uma alteração adicional. Dada as limitações já descritas sobre a correlação entre as oportunidades de diferenciação de produtos e seu valor unitário, foi calculado o coeficiente de variação dos valores unitários das exportações de acordo com os países destino. O objetivo desse procedimento é simples: verificar se um mesmo produto pode ser vendido por diferentes preços para diferentes parceiros comerciais. Uma maior variação dos valores unitários sugere que o produto NCM de oito dígitos possui mais oportunidades de diferenciação e diferentes qualidades.

Assim, o $I Q X_{i}$ é:

$$
I Q X_{i}=V U_{i} \cdot C V_{i} \cdot s_{i}
$$

E finalmente, é preciso verificar quais os setores exportadores que conseguiram se integrar às trajetórias de desenvolvimento associadas à ampliação da elasticidade da demanda. Para identificar o desempenho do setor $i$ e classificá-lo nas trajetórias, vamos tomar a média de $I D X_{i}$ e $I Q X_{i}$ no período 2000-2012, ou seja, $\overline{I D X_{l}}$ e $\overline{I Q X_{l}}$ e multiplicá-lo pela variação da medida de diversificação, $H H^{\prime}{ }_{i}$, e da medida de diferenciação, $V U_{i}$. As variações, $\Delta H H^{\prime}{ }_{i}$ e $\Delta V U_{i}$, serão obtidas pela diferença entre as médias de cada variável no período 2000-2004 e 2009-2012, ou seja, $\Delta H H^{\prime}{ }_{i}=\overline{H H_{l}^{\prime 2009-2012}}-\overline{H H_{l}^{\prime 2000-2004}}$ e $\Delta V U_{i}=$ $\overline{V U_{l}^{2009-2012}}-\overline{V U_{l}^{2000-2004}}$. Como $\overline{I D X_{l}}$ e $\overline{I Q X_{l}}$ são positivos, determinado setor terá desempenhado um comportamento compatível com as trajetórias de desenvolvimento se $\Delta H H^{\prime}{ }_{i}$ e $\Delta V U_{i}$ forem positivos.

Portanto, se $T_{2}=\overline{I D X_{l}} \cdot \Delta H H^{\prime}{ }_{i}>0$ e $T_{3}=\overline{I Q X_{l}} \cdot \Delta V U_{i}>0$ então o setor $i$ estará inserido na segunda e terceira trajetórias de desenvolvimento $\left(T_{2}\right)$ e $\left(T_{3}\right)$, respectivamente. A próxima seção apresenta os resultados obtidos com a metodologia descrita e discute os fatores que levam à diversificação e diferenciação da pauta de exportações.

\section{Resultados}

Antes de apresentar os resultados setoriais de diversificação e diferenciação, é necessário comparar como o desempenho brasileiro nas exportações se encontra em relação aos demais países exportadores. Em termos de diversificação da pauta exportadora, o Gráfico 1 apresenta o número de produtos exportados por cada país de acordo com o nível de seis dígitos do Sistema Harmonizado (SH-6). Um produto é contado caso tenha sido exportado para pelo menos um país de destino em determinado ano com o valor mínimo de US\$ 10 mil. Considerando a média dos anos finais de cada subperíodo considerado neste artigo, 2004, 2008 e 2012, o Brasil exportou cerca de 4.200 produtos de um total aproximado de 5.000 produtos. Dentre 155 países que exportaram pelo menos 100 diferentes produtos SH-6, o país ficou em $28^{\circ}$ dentre os $20 \%$ que mais diversificaram sua pauta de exportações. Estados Unidos, Índia, Espanha, Reino Unido e Bélgica foram os cinco países que com a pauta exportadora mais diversificada neste período.

Por sua vez, a comparação das exportações brasileiras em termos de diferenciação e qualidade das exportações, a referência utilizada será o Índice de Complexidade Econômica (ECI) elaborado por Hausmann, Hidalgo et al. (2014) e disponível http://atlas.media.mit.edu/. Para os autores, a complexidade de uma economia é associada com a quantidade e multiplicidade de tipos de conhecimento que consegue incorporar em seus indivíduos e instituições. A complexidade econômica expressa a composição da estrutura produtiva e a capacidade que um país possui em acumular conhecimento e combiná-lo de diferentes formas. Por sua vez, o ECI é calculado considerando informações sobre a diversidade das exportações de um determinado país em conjunto com as informações sobre o número de países que são 
capazes de produzir um determinado produto. Nesse último caso, produtos fabricados por poucos países exigem um conjunto de conhecimentos e know-how para serem produzidos que não é acessível a todos os países, caso contrário todos o produziriam. Portanto, países mais diversificados e que produzam bens menos ubíquos simultaneamente são considerados mais complexos de acordo com este índice ${ }^{4}$. Na comparação internacional que mede a sofisticação e complexidade dos países de acordo com sua cesta de exportação, o Brasil fica na $44^{a}$ posição, apenas entre os $36 \%$ com estrutura produtiva mais complexa entre 122 países.

\section{Gráfico 1- Número de Produtos Exportados - Sistema Harmonizado 6 dígitos; Média dos anos 2004, 2008 e 2012}

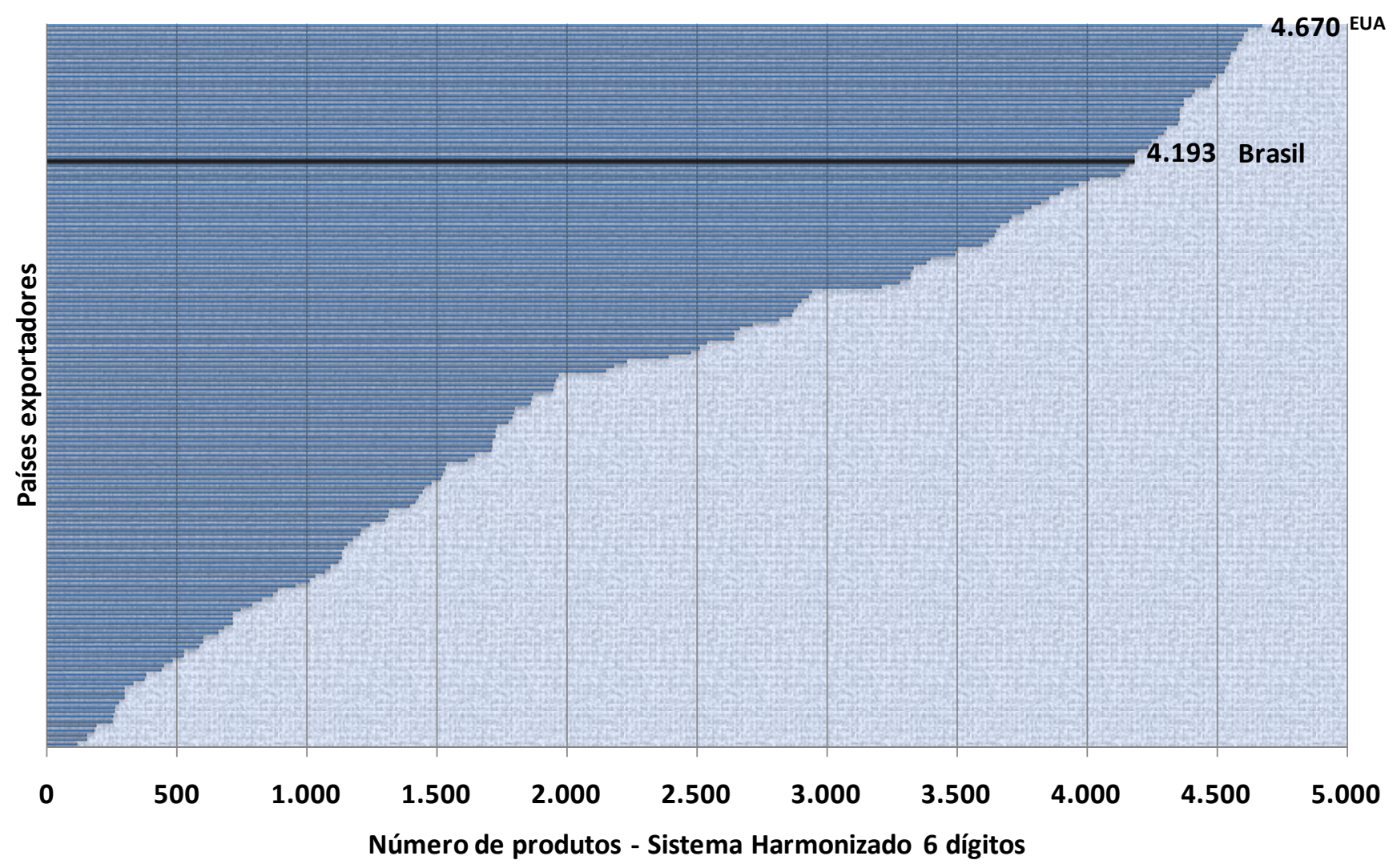

Fonte: WITS - World Integrated Trade Solutions em http://wits.worldbank.org/ - acessado em 27/04/2016.

Portanto, comparado internacionalmente, o Brasil possui uma estrutura exportadora diversificada, considerando que exporta cerca de $90 \%$ do número de produtos $\mathrm{SH}-6$ dígitos que o país mais diversificado - os Estados Unidos - exporta ${ }^{5}$. No índice que mede a sofisticação relativa dessa cesta de exportação (ECI), o Brasil fica para trás no ranking de países. Isso sugere que embora o país consiga exportar um número grande de variedades, cada produto possui diferentes modos no qual pode ser produzido - com diferentes intensidades de insumos, sejam eles capital, trabalhadores, tecnologia e conhecimento - e o Brasil, de modo geral, ainda está distante da fronteira tecnológica. Essa questão voltará adiante quando for apresentada a comparação dos índices de diferenciação e qualidade dos produtos exportados e importados pelo país.

Após esse breve exercício para situar o Brasil dentro do contexto internacional em termos de diversificação e sofisticação de suas exportações, vamos identificar dentro da estrutura comercial

\footnotetext{
${ }^{4}$ A explicação e o cálculo detalhados do Índice de Complexidade Econômica podem ser encontrados em "The Atlas of Economic Complexity”. http://atlas.media.mit.edu acessado em 27/04/2016.

${ }^{5}$ A sobreposição de produtos exportados por Brasil e Estados Unidos não diz nada em relação à composição da pauta de exportação de ambos os países, ou seja, não significa que a proporção desses produtos no total das exportações seja a mesma.
} 
brasileira quais os setores que conseguiram se integrar às trajetórias associadas à elasticidade-renda da demanda. O Gráfico 2 apresenta a média dos índices $I D X_{i}$ e $I Q X_{i}$ para os setores exportadores do Brasil no período de 2000 a 2012. Para uma melhor apresentação gráfica, os valores apresentados foram transformados pela aplicação do logaritmo natural, ou seja, no gráfico são apresentados os $\ln \left(I D X_{i}\right)$ e $\ln \left(I Q X_{i}\right)$.

Os setores com melhor $I D X_{i}$ foram o setor 10 - Produtos Alimentícios, o setor 24 - Metalurgia, o setor 29 - Veículos Automotores, o setor 01 - Agricultura e Pecuária, o setor 28 - Máquinas e Equipamentos, o setor 20 - Produtos Químicos e o setor 07 - Extração de Minerais Metálicos. Os setores mais diversificados e relevantes da pauta exportadora brasileira são heterogêneos em relação à intensidade tecnológica e à classificação que considera os padrões setoriais de mudanças técnicas elaborada originalmente por Pavitt (1984) ${ }^{6}$. Por exemplo, três setores pertencem ao grupo de Média-alta intensidade tecnológica de acordo com a classificação elaborada pela OCDE (setor 20 - Produtos Químicos, setor 28 - Máquinas e Equipamentos e setor 29 - Veículos Automotores), enquanto um setor é classificado em cada uma destas categorias, Baixa tecnologia (setor 10 - Produtos Alimentícios), Média-baixa (setor 24 Metalurgia), Indústrias extrativas (setor 07 - Extração de Minerais Metálicos) e Indústrias agrícolas (setor 01 - Agricultura e Pecuária). De acordo com a classificação elaborada por Keith Pavitt, quatros setores são Intensivos em Escala, sendo que dois tem processo contínuo (setor 20 - Produtos Químicos e setor 24 - Metalurgia) e dois outros, processo descontínuo (setor 10 - Produtos Alimentícios e setor 29 - Veículos Automotores), apenas um setor é Difusor de Progresso Técnico (setor 28 - Máquinas e Equipamentos).

Já os setores mais relevantes em termos de diferenciação e qualidade, com maiores $I Q X_{i}$ foram o setor 30 - Equipamentos de Transporte, o setor 26 - Informática, Eletrônicos e Ópticos, o setor 29 - Veículos Automores, o setor 21 - Farmoquímicos e Farmacêuticos, o setor 28 - Máquinas e Equipamentos e o setor 32 - Produtos Diversos. Dois setores são de Alta tecnologia e Baseados em Ciência (setor 21 Farmoquímicos e Farmacêuticos e o setor 26 - Informática, Eletrônicos e Ópticos), outros três são de Média-alta tecnologia e Intensivos em Escala - processo descontínuo (setor 28 - Máquinas e Equipamentos, o setor 29 - Veículos Automores e o setor 30 - Equipamentos de Transporte) e um setor de Baixa tecnologia e Dominado pelos Fornecedores (setor 32 - Produtos Diversos). Dos seis mais relevantes à terceira trajetória de desenvolvimento (diferenciação), apenas dois apareceram entre os mais relevantes à segunda trajetória de desenvolvimento (diversificação). No entanto, considerando 27 setores, a correlação entre os dois índices é maior, de 0,50 . Do Gráfico 1 podemos observar que os setores estão mais concentrados no canto inferior direito, abaixo da linha de $45^{\circ}$, indicando que os setores foram melhores na diversificação do que na diferenciação de produtos.

\footnotetext{
${ }^{6}$ A classificação utilizada aqui é retirada da Nota Técnica do IPEA,”Classificações tecnológicas: uma sistematização”, que apresenta uma versão modificada da classificação original de Pavitt, baseada em trabalhos de Robinson (2003), Dosi et all (2008) e Botazzi et al (2010). Como a classificação considera apenas a indústria de transformação, optou-se por adicionar duas classes relacionadas às Indústrias Extrativas e as atividades ligadas à Agricultura e Pecuária.
} 


\section{Gráfico 2 - Índice de Diversificação e Índice de Diferenciação e Qualidade das Exportações Brasileiras - média 2000 a 2012}

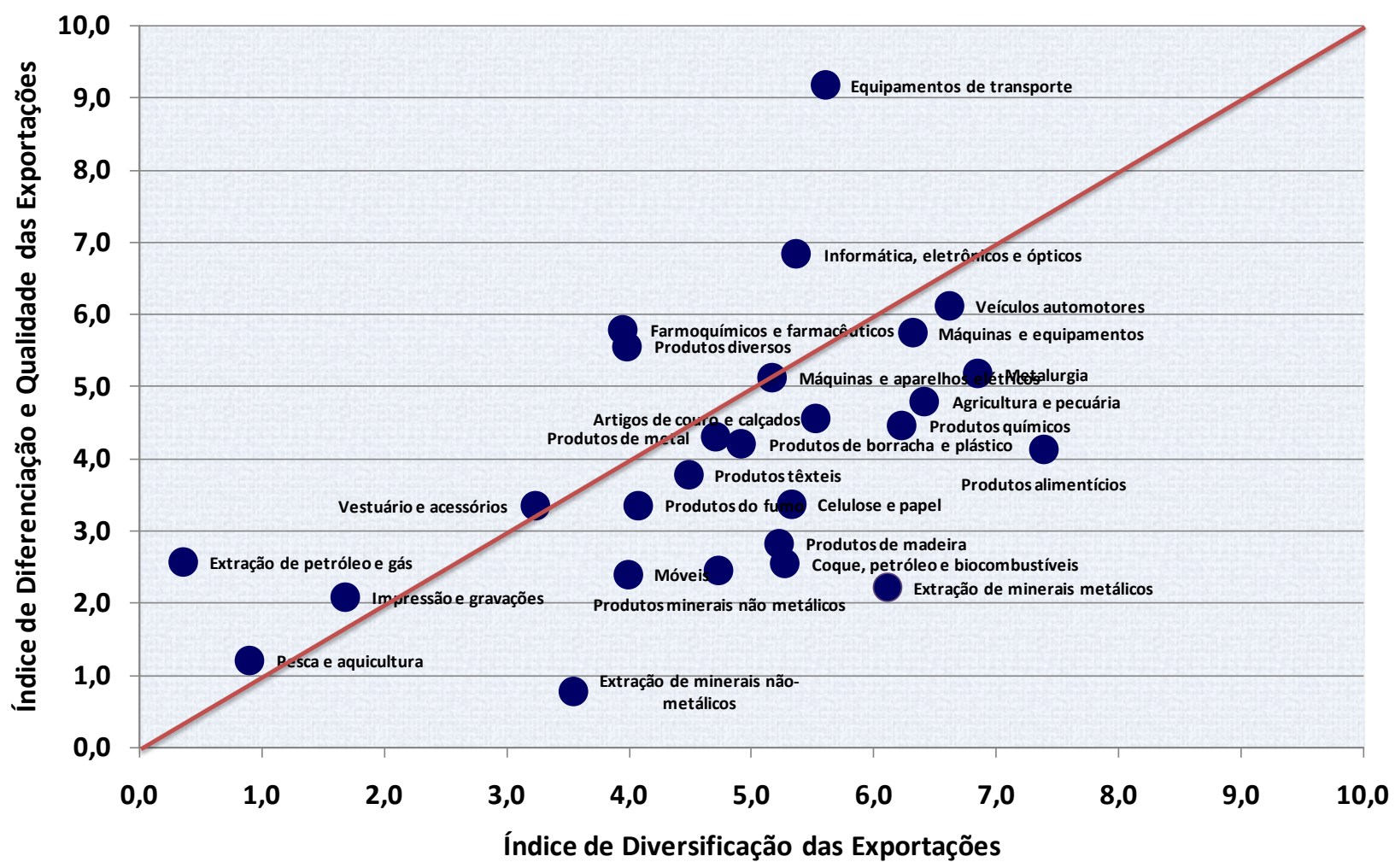

Fonte: Secex/MDIC. Elaboração própria.

É interessante comparar como os setores exportadores estão posicionados nestas duas trajetórias associadas à ampliação da elasticidade da demanda em relação aos produtos que o país importa ${ }^{7}$. $\mathrm{O}$ Gráfico 3 apresenta a média dos índices setoriais de importação, $I D M_{i}$ e $I Q M_{i}$, transformados pelo logaritmo natural. A correlação entre as duas séries de índices de importação foi maior $(0,79)$ do que a encontrada para os mesmos índices de exportação.

Os setores mais diversificados e relevantes na cesta de importação do país foram o setor 20 - Produtos Químicos, o setor 26 - Informática, Eletrônicos e Ópticos, o setor 28 - Máquinas e Equipamentos, o setor 29 - Veículos Automotores, o setor 19 - Coque, Petróleo e Biocombustíveis e o setor 24 - Metalurgia. Assim como nas exportações, três setores são classificados como Média-alta tecnologia (setor 20 Produtos Químicos, setor 28 - Máquinas e Equipamentos, setor 29 - Veículos Automotores), outros dois são de Média-baixa tecnologia (setor 19 - Coque, Petróleo e Biocombustíveis e setor 24 - Metalurgia) e um de Alta-tecnologia (setor 26 - Informática, Eletrônicos e Ópticos). Na classificação de Pavitt, a categoria de Intensivos em Escala dominou da mesma forma como ocorreu nas exportações. Três setores são de processo contínuo (setor 19 - Coque, Petróleo e Biocombustíveis, setor 20 - Produtos Químicos e setor 24 - Metalurgia) e um outro de processo descontínuo (setor 29 - Veículos Automotores), outro classificado como Difusor de Progresso Técnico (setor 28 - Máquinas e equipamentos) e outro como Baseado em Ciência (setor 26 - Informática, Eletrônicos e Ópticos).

No contexto da terceira trajetória, os setores mais relevantes de importações foram o setor 30 Equipamentos de Transporte, o setor 26 - Informática, Eletrônicos e Ópticos, o setor 21- Farmoquímicos e Farmacêuticos, o setor 28 - Máquinas e Equipamentos, o setor 27 - Máquinas e Aparelhos Elétricos e o setor 29 - Veículos Automotores. Dentre estes setores, dois são de Alta-tecnologia e Baseados em

\footnotetext{
7 Todos os índices e medidas calculados para os produtos importados seguiram a mesma metodologia descrita anteriormente na seção 3.
} 
Ciência (setor 21- Farmoquímicos e Farmacêuticos e o setor 26 - Informática, Eletrônicos e Ópticos) e os outros quatro são de Média-alta tecnologia na classificação OCDE. Na classificação de Pavitt, três setores são Intensivos em Escala - processo descontínuo (setor 28 - Máquinas e Equipamentos, setor 29 Veículos Automotores e setor 30 - Equipamentos de Transporte) e o outro é Difusor de Progresso Técnico (setor 27 - Máquinas e aparelhos elétricos).

\section{Gráfico 3 -Índice de Diversificação e Índice de Diferenciação e Qualidade das Importações Brasileiras - média 2000 a 2012}

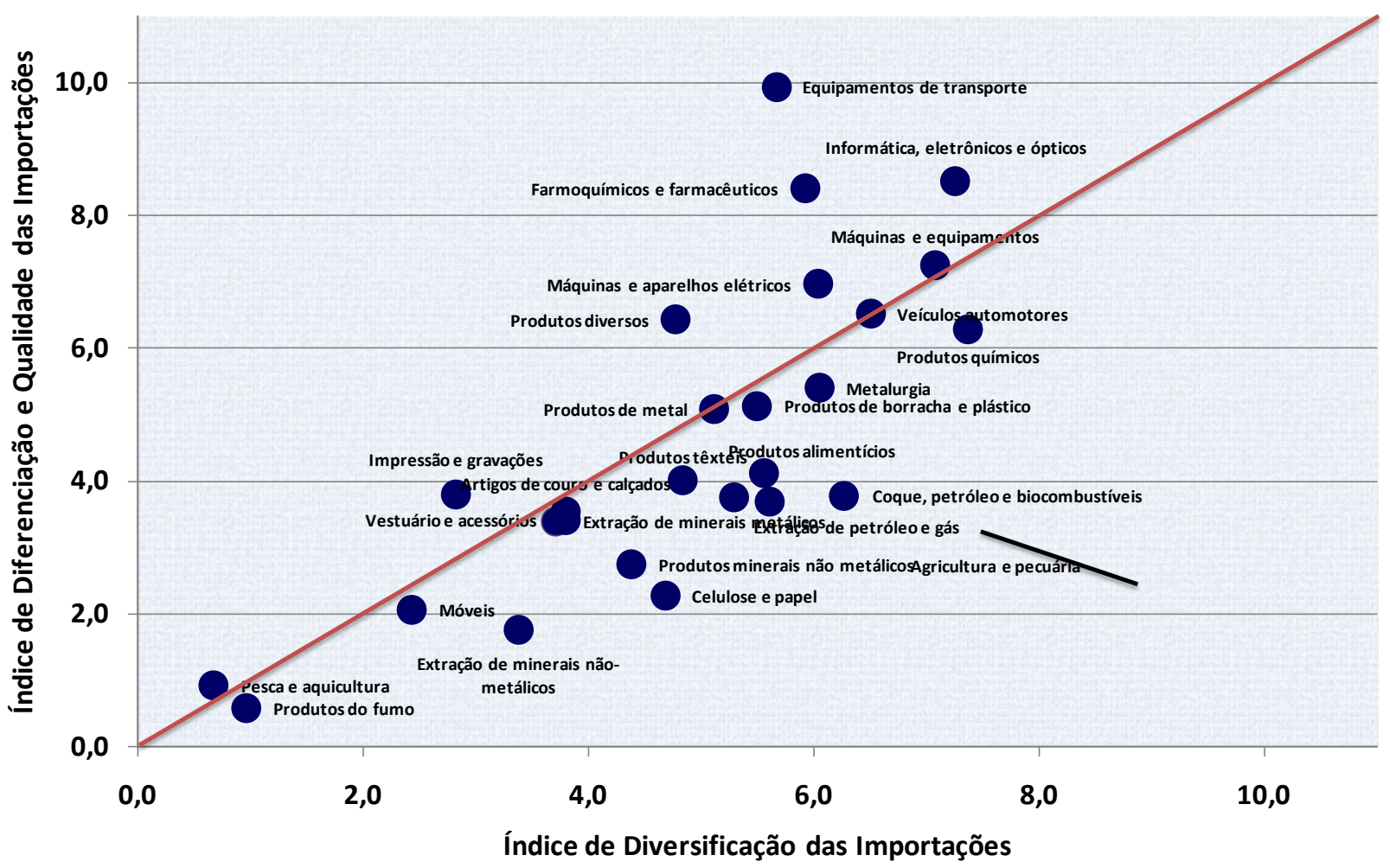

Fonte: Secex/MDIC. Elaboração própria.

Dentre os setores com melhores desempenhos de diversificação, diferenciação e relevância no comércio, alguns pontos podem ser destacados. Em relação à diversificação dos setores nas exportações, quatro setores são ligados a recursos naturais direta ou indiretamente, o que não chega a ser nenhuma surpresa, dada à grande competitividade que o país detém nesta área. O setor 10 - Produtos Alimentícios, que apesar de classificado dentro da indústria de transformação possui grande dependência de insumos originados no setor 01 - Agricultura e Pecuária. Já este último setor juntamente com o setor 07 - Extração de Minerais Metálicos das Indústrias extrativas e o setor 24 - Metalurgia adquiriram maior capacidade de competir no mercado exterior como conseqüência dos investimentos realizados nas últimas décadas, das pesquisas realizadas pela Embrapa (Empresa Brasileira de Pesquisa Agropecuária) que possibilitaram a expansão da fronteira agrícola e produtividade da agricultura e pecuária brasileiras e a incorporação de tecnologias modernas em todas as etapas dessas atividades. Pesquisas posteriores podem verificar o quanto da diversificação do setor 28 - Máquinas e Equipamentos pode ter sido influenciado pelos bens de capital para a agricultura, a indústria extrativa e de energia. De acordo com a Pesquisa Industrial Mensal Produção Física (PIM-PF) a produção dos Bens de Capital Agrícolas aumentou cerca de 80\% entre 2000 e 2008, enquanto a produção dos Bens de Capital para o setor de Energia Elétrica aumentou 175\% entre 2002 e 2008, acima do crescimento da produção dos Bens de Capital para fins industrial em geral ${ }^{8}$.

\footnotetext{
${ }^{8}$ Esta série foi descontinuada em fevereiro de 2014. O setor foi atingido pela crise de 2008, de modo que seus índices em 2012 são inferiores aqueles registrados em 2008. Os Bens de Capital Agrícolas apresentaram índices 7\% inferiores neste último
} 
Já nas importações, os setores mais diversificados são classificados como Alta ou Média-alta tecnologias e apenas dois dos seis setores pertencem à classe de Média-baixa tecnologia. Portanto, as especializações foram diferentes entre os dois fluxos de comércio, mesmo considerando que três setores se repetem dentre os mais relevantes. Os setores 24 - Metalurgia, 28 - Máquinas e Equipamentos e o 29 - Veículos Automotores estão entre os mais diversificados tanto nas exportações quanto nas importações.

Essa similaridade de desempenho dos setores aumenta quando se olha para os índices de diferenciação $\left(I Q X_{i}\right.$ e $\left.I Q M_{i}\right)$. Dos seis principais setores das exportações, apenas o setor 32 - Produtos Diversos não aparece entre os mais relevantes na pauta de importações. Este setor de Baixa tecnologia e Dominado por Fornecedores é substituído pelo setor 27 - Máquinas e Aparelhos Elétricos, classificado como Média-alta tecnologia e Difusor do progresso técnico.

Os resultados da diversificação setorial são mais relacionados com a composição estrutural dos fluxos comerciais enquanto os resultados da diferenciação têm um componente mais específico às características do setor. Por isso, os resultados do segundo índice são mais homogêneos (mais setores se repetem) que os do primeiro. Em outras palavras, a qualidade e diferenciação dependem das características técnicas e de serviços dos produtos, enquanto a diversificação de produtos intrassetores depende das capacitações e vantagens competitivas que o setor possui e isso determina a composição das cestas comercializadas.

Para verificar essa afirmação, podemos usar o índice de similaridade das exportações e importações (ISEM) de Finger-Kreinin (1979) para determinar o quão similar as exportações brasileiras são em comparação com suas importações. Este índice varia entre zero, quando ocorre a máxima desigualdade, e um quando há igualdade entre as duas distribuições. Portanto, quanto maior o ISEM maior é a similaridade da estrutura da pauta de exportações à da pauta importadora.

$$
I S E M=1-\left(1 / 2 \sum_{i=1}^{n}\left|x_{i}-m_{i}\right|\right)
$$

Onde $x_{i}$ e $m_{i}$ são a participação relativa do setor $i$ CNAE a dois dígitos nas exportações e nas importações, respectivamente.

A média do ISEM no período 2000 a 2012 é de 0,52. Mais importante que o valor médio é a relativa estabilidade registrada no período. A composição das exportações apresenta maior similaridade com a das importações no triênio 2006-2008 (0,55-0,56) e apresenta a maior dissimilaridade no ano de $2011(0,48)$. O ISEM apresenta correlação positiva com a participação dos produtos manufaturados na pauta de exportações e correlação negativa com a participação dos produtos primários. Isso sugere que, quando o país exporta uma proporção maior de bens manufaturados, sua pauta exportadora torna-se mais similar à cesta que importa e quando a proporção de bens primários aumenta, a composição das duas pautas se distancia. O índice sugere a existência de diferentes especializações no que o país exporta e importa, de modo que as chances de os setores de maior de diversificação das exportações e importações serem os mesmos são menores.

Para averiguar se a qualidade e diferenciação são específicas aos produtos que cada setor comercializa, podemos calcular qual a correlação entre os Índices de Diferenciação e Qualidade setoriais das exportações e importações. A correlação entre os $I Q X_{i}$ e $I Q M_{i}$ médios do período 2000-2012 foi de 0,86, bem maior que a correlação entre os índices de Diversificação, IDX e IDM, do período, que foi de 0,52. Isso mostra que os valores unitários associados à relevância do setor nas pautas de comércio são mais dependentes dos tipos de produtos comercializados. Produtos com mais oportunidades de diferenciação e “escada” mais longa possui Valor Unitário e Coeficiente de Variação maiores que produtos unidimensionais de "escada” mais curta.

período, enquanto o índice dos Bens de Capital para o Setor de Energia foi cortado pela metade. O índice de Bens de Capital para Fins Industriais diminuiu em 9\%. 
Mas a evidência da existência desse aspecto produto-específico significa que existe uma "cesta de produtos” que o país precise reproduzir como uma condição para manter um processo de mudança estrutural? De acordo com os conceitos em Saviotti e Meltcalfe (1984), Guimarães (1981) e Grossman e Helpman (1991) podemos afirmar que os produtos (e setores) nos quais os países se especializam são importantes para o desenvolvimento. As externalidades - spillovers de conhecimento e know-how, os encadeamentos na relação de insumo-produto e o aumento de trabalhadores capacitados - podem levar a aumentos da eficiência produtiva de um país ou região. Além disso, a extração de rendas das atividades que possam explorar as economias de escala pode ser mais relevante que as vantagens comparativas. Porém, esses dois fatores não são associados a todos os tipos de bens e serviços.

Apesar de se poder afirmar que a “cesta” de bens que um país exporta é relevante para seu desenvolvimento, identificar quais são os produtos ideais que entram na sua composição não é tarefa simples. Usualmente, dois fatos estilizados são amplamente utilizados para que a resposta a essa questão seja rápida e fácil. O melhor seria a especialização em bens sofisticados cuja produção seja intensiva em alta tecnologia e de alta produtividade, enquanto a exportação de recursos naturais e seus derivados poderia conter uma “maldição” que levaria ao baixo crescimento ou estagnação.

Hausmann, Hwang e Rodrik (2006) desenvolveram um índice que associa alguns bens comercializados a níveis de produtividade maiores que o de outros produtos. E encontraram que os países especializados nos bens de maior produtividade apresentaram maior crescimento econômico. O índice PRODY é calculado considerando as médias ponderadas do PIB per capita dos países que exportam determinado produto. Com isso é possível gerar para cada produto uma medida que o associa a qual tipo de país, em nível de renda, é mais provável que o exporte. Depois, a cesta de exportação de cada país é medida de acordo com o índice $P R O D Y$ dos produtos que a compõem, cujo índice é denominado de EXPY pelos autores. Assim, o índice EXPY é o nível de produtividade associado à especialização de cada país. Países com maior índice EXPY possuem uma cesta de exportação mais adequada ao desenvolvimento econômico que pode servir como guia para os países em desenvolvimento.

No entanto, existem críticas a essa visão pré-determinada, na qual existiriam produtos definidos $a$ priori que levariam ao desenvolvimento. Por exemplo, a tentativa de entrada em um setor maduro com elevados índices PRODY podem não resultar em nenhuma apropriação de rendas e aproveitamento de externalidades. Lederman e Maloney (2012) falam da tentativa da Nokia entrar no mercado de televisores na década de 1980 - um produto com sofisticação elevada - mas que por estar saturado não resultou nos lucros esperados. Porém, foram os telefones celulares produzidos numa pequena divisão da empresa e sem nenhum PRODY ou EXPY associado - porque esse produto simplesmente não existia - que se "revelou” um produto dinâmico capaz de gerar valor e pleno de possibilidade de incorporar inovações. Portanto, esses índices são indicadores "revelados”, que podem explicar o caminho de desenvolvimento percorrido por um país, mas não garantem que adotar a produção deste bem trará os mesmos benefícios.

Ao contrário, a tentativa de exportar uma cesta de produtos vista a priori como adequada pode ser adotada por diversos países ao mesmo tempo. Isso pode transformar os produtos em commodities industriais, com preços reduzidos e baixa possibilidade de geração de valor. Isso sugere que a simples reprodução da estratégica asiática, seguida pela China e outros países asiáticos se esgotou. Além disso, outros fatores influenciam a composição da pauta exportadora dos países desenvolvidos - custos de transporte, proteções e subsídios e a crescente fragmentação da produção internacionalmente distribuída (Lederman e Maloney, 2012).

Por sua vez, a especialização nas exportações de recursos naturais normalmente é vista como a causa de um desempenho econômico que não é capaz de se sustentar no longo prazo. As atividades extrativas são intensivas em capital, não demandam uma grande quantidade de trabalhadores capacitados, as oportunidades de diferenciação de produtos - e a expansão da elasticidade da demanda - são pequenas e por isso, as inovações são concentradas no processo de produção, com possibilidades reduzidas de spillovers. Os países exportadores de recursos naturais normalmente concentram sua pauta de exportação 
e sofrem com a grande volatilidade dos preços internacionais, trazendo problemas de restrição de balanço de pagamentos ao longo do tempo.

No entanto, existem experiências heterogêneas com países que decidiram explorar suas riquezas naturais. Lederman e Maloney (2008) mostram que altos níveis de renda foram alcançados por países exportadores e importadores líquidos de produtos baseados em recursos naturais. Diversos países também conseguiram transferir tecnologia das indústrias de recursos naturais para outros setores, promovendo uma dinâmica capaz de aumentar o PIB per capita. Países como Canadá, Austrália, Noruega, Suécia, etc, conseguiram completar essa transição enquanto países da América Latina, inclusive o Brasil, não conseguiram. Os distintos resultados se devem mais às capacidades de aprendizado e de gerar e estocar conhecimento e know-how nos trabalhadores, empresas, universidades, órgãos governamentais, entre outras instituições, do que a especialização em um tipo de produto. Já os efeitos da concentração das exportações é um problema mais geral e não apenas restrito aos produtos baseados em recursos naturais (Lederman e Malone, 2012).

Portanto, o produto exportado é importante para o desenvolvimento, dado sua oportunidade de diferenciação e aumento da qualidade. E mais importante que os tipos de produtos da cesta inicial é a capacidade de transferir o conhecimento e know-how utilizado na produção de um produto ou setor para outro. Hidalgo et all (2007) usa a analogia de uma floresta e os macacos que nela vivem para explicar como se dá essa transferência. Macacos seriam empresas que viveriam em árvores ou produtos da economia. O desenvolvimento tem mais chances nas áreas mais densas da floresta, onde as árvores estão mais próximas, possibilitando aos macacos pularem de uma árvore com maior facilidade. Ou seja, em um espaço abstrato de produtos, existem setores nos quais a utilização do mesmo conjunto de insumos e capacitações para a produção de um determinado produto permite às empresas entrarem na produção de outro produto que utiliza um conjunto similar de capacitações e insumos. Mas, novamente, não é apenas o tipo de produto que permite o salto de uma árvore a outra como pode ser entendido num primeiro momento. Isso por que não há garantia de que estar na parte mais densa da floresta significa que será fácil alcançar as demais árvores (Lederman e Malone, 2012). É preciso que os macacos possuam capacitações para realizar os saltos entre as árvores. Em trabalhos mais recentes, Hausmann e Hidalgo (2010) e Hidalgo (2015) mudaram o foco das distâncias entre as árvores para a capacidade de acumulação de conhecimento e know-how em rede de pessoas e de empresas como determinante de um salto de sucesso. O "que produzir" é importante, mas sem o elemento-chave, o "como produzir" o desenvolvimento não ocorre, pois não há diversificação e nem diferenciação de produtos.

O “como” produzir diferentes produtos pode ser mensurado pela comparação entre os Valores Unitários de Exportação e Importação ( $V U M$ e $V U X$, respectivamente), que são apresentados na Tabela 1. Valores acima da unidade indicam que a qualidade e sofisticação dos produtos exportados foram maiores no período em relação aos produtos importados, e valores abaixo da unidade indicam o contrário. 
Tabela 1 - Diferenciação e Qualidade Comparada - Exportação e Importação

Razão Valor Unitário Ponderado (Em Reais de 2012) - Diferenciação e qualidade - Exportações e Importações

\begin{tabular}{|c|c|c|c|c|c|}
\hline Cnae 2.0 & Descrição setores Cnae 2.0 & $2000-2012$ & 2000-2004 & $2005-2008$ & 2009-2012 \\
\hline 01 & Agricultura e pecuária & 0.63 & 0.77 & 0.63 & 0.50 \\
\hline 02 & Produção florestal & 0.48 & 0.29 & 0.55 & 0.72 \\
\hline 03 & Pesca e aquicultura & 3.10 & 1.35 & 2.85 & 6.73 \\
\hline 05 & Extração de carvão mineral & 3.95 & 3.55 & 4.58 & 4.17 \\
\hline 06 & Extração de petróleo e gás & 0.81 & 0.77 & 0.79 & 0.89 \\
\hline 07 & Extração de minerais metálicos & 0.04 & 0.04 & 0.03 & 0.06 \\
\hline 08 & Extração de minerais não-metálicos & 0.32 & 0.18 & 0.50 & 1.65 \\
\hline 10 & Produtos alimentícios & 0.42 & 0.43 & 0.40 & 0.41 \\
\hline 11 & Bebidas & 0.60 & 0.56 & 0.61 & 0.68 \\
\hline 12 & Produtos do fumo & 0.38 & 0.30 & 0.38 & 0.59 \\
\hline 13 & Produtos têxteis & 1.02 & 0.90 & 1.05 & 1.27 \\
\hline 14 & Vestuário e acessórios & 1.45 & 1.01 & 1.48 & 2.10 \\
\hline 15 & Artigos de couro e calçados & 1.10 & 1.02 & 1.29 & 1.08 \\
\hline 16 & Produtos de madeira & 0.48 & 0.44 & 0.55 & 0.53 \\
\hline 17 & Celulose e papel & 0.54 & 0.55 & 0.53 & 0.53 \\
\hline 18 & Impressão e gravações & 1.32 & 1.03 & 1.36 & 2.10 \\
\hline 19 & Coque, petróleo e biocombustíveis & 0.84 & 0.83 & 0.83 & 0.88 \\
\hline 20 & Produtos químicos & 0.61 & 0.65 & 0.56 & 0.61 \\
\hline 21 & Farmoquímicos e farmacêuticos & 0.43 & 0.51 & 0.38 & 0.39 \\
\hline 22 & Produtos de borracha e plástico & 0.65 & 0.57 & 0.63 & 0.85 \\
\hline 23 & Produtos minerais não metálicos & 0.31 & 0.23 & 0.32 & 0.60 \\
\hline 24 & Metalurgia & 0.40 & 0.25 & 0.27 & 1.02 \\
\hline 25 & Produtos de metal & 0.70 & 0.72 & 0.50 & 0.92 \\
\hline 26 & Informática, eletrônicos e ópticos & 0.90 & 0.72 & 1.15 & 0.93 \\
\hline 27 & Máquinas e aparelhos elétricos & 0.32 & 0.26 & 0.35 & 0.53 \\
\hline 28 & Máquinas e equipamentos & 0.51 & 0.40 & 0.53 & 0.79 \\
\hline 29 & Veículos automotores & 0.76 & 0.72 & 0.77 & 0.84 \\
\hline 30 & Equipamentos de transporte & 0.98 & 2.32 & 0.27 & 3.89 \\
\hline 31 & Móveis & 0.38 & 0.44 & 0.35 & 0.34 \\
\hline 32 & Produtos diversos & 0.58 & 0.53 & 0.50 & 0.76 \\
\hline
\end{tabular}

Fonte: Secex/MDIC. Elaboração própria.

Considerando o período todo exposto na primeira coluna, podemos ver que apenas seis setores apresentaram maior qualidade e sofisticação de seus produtos exportados em relação ao que o país importa. O setor 05 - Extração de Carvão Mineral e o setor 03 - Pesca e Aquicultura apresentaram os maiores valores comparativos, seguidos pelo setor 14 - Vestuário e Acessórios, o setor 18 - Impressão e Gravações e o setor 15 - Artigos de Couros e Calçados. O setor 13 - Produtos Têxteis também apresentou um valor positivo, embora muito próximo da unidade. Novamente, exportações de setores baseados em recursos naturais e setores tradicionais da indústria de transformação mostraram maior qualidade em relação às importações. Portanto, ainda existe uma considerável distância entre o conjunto de capacitações e conhecimentos incorporado e utilizado nas exportações e aquele utilizado pelos países dos quais o Brasil importa seus produtos, lembrando que estes últimos são em sua maioria do setor manufatureiro.

Por fim, é necessário identificar quais setores exportadores que conseguiram se integrar às trajetórias de desenvolvimento associadas à elasticidade-renda da demanda. Ou seja, quais os setores que conseguiram ampliar a diversificação e a diferenciação e qualidade dos produtos que exportaram no período. A Figura 1, abaixo, auxilia a visualização dos setores CNAE 2.0 a dois dígitos de acordo com a classificação OCDE de intensidade tecnológica e a classificação elaborada por Pavitt. Os quadrados pretos com a letra $\mathrm{N}$ identificam os setores que não se integraram às trajetórias de desenvolvimento, enquanto os quadrados brancos com a letra $\mathrm{S}$ identificam os setores que conseguiram se integrar. 
Figura 1 - Integração setorial às trajetórias de desenvolvimento associadas à elasticidade-renda da demanda

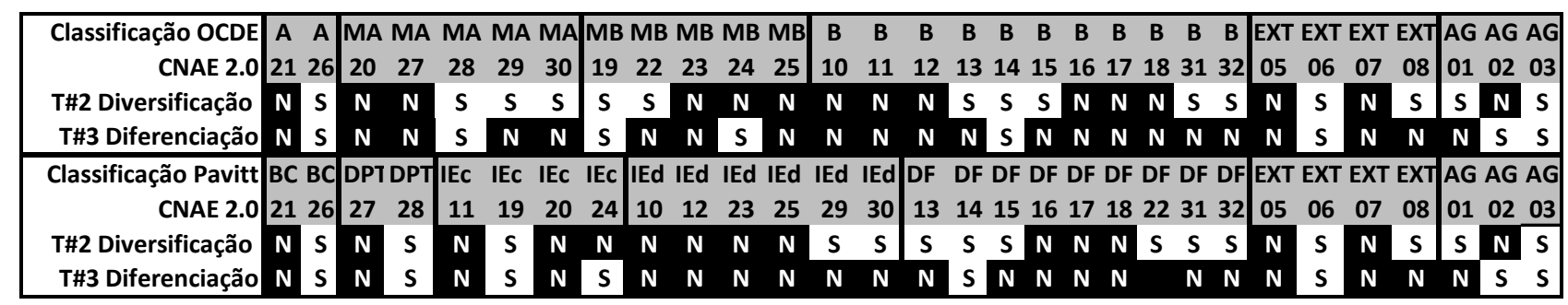

Fonte: Secex/MDIC. Elaboração própria.

\begin{tabular}{|c|c|c|c|c|}
\hline \multicolumn{5}{|c|}{ Legenda - Figura 1} \\
\hline \multicolumn{5}{|c|}{ Setores CNAE 2.0 - Dois dígitos } \\
\hline 01 & Agricultura e pecuária & & Produtos têxteis & 23 İProdutos minerais não metálicos \\
\hline 02 & Produção florestal & 14 & Vestuário e acessórios & 24 Metalurgia \\
\hline 03 & Pesca e aquicultura & 15 & Artigos de couro e calçados & 25 Produtos de metal \\
\hline 05 & Extração de carvão mineral & 16 & Produtos de madeira & 26 Informática, eletrônicos e ópticos \\
\hline & Extração de petróleo e gás & & Celulose e papel & 27 Máquinas e aparelhos elétricos \\
\hline 07 & Extração de minerais metálicos & & Impressão e gravações & 28 Máquinas e equipamentos \\
\hline 08 & Extração de minerais não-metálicos & 19 & Coque, petróleo e biocombustíveis & 29 Veículos automotores \\
\hline-10 & Produtos alimentícios & 20 & Produtos químicos & 30 Equipamentos de transporte \\
\hline 11 & Bebidas & 21 & Farmoquímicos e farmacêuticos & 31 Móveis \\
\hline & Produtos do fumo & 22 & Produtos de borracha e plástico & 32 Produtos diversos \\
\hline \multicolumn{5}{|c|}{ Taxonomia elaborada por Pavit (1984) - Padrões Setoriais de Mudanças Técnicas } \\
\hline$\overline{\mathrm{BC}}$ & Baseado em ciência & IEC & Intensivo em escala (processo contínuo) & DF Dominado pelos fornecedores \\
\hline $\mathrm{DPT}$ & Difusor de progresso técnico & IEd & Intensivo em escala (processo descontínud & EXTindústrias Extrativas \\
\hline & & & & AG Átividades Agrícolas, Pecuária, etc \\
\hline \multicolumn{5}{|c|}{ Intensidade Tecnológica elaborada pela Organização para Cooperação e Desenvolvimento Econômico (OCDE) } \\
\hline A & Alta tecnologia & $\mathrm{MB}$ & Média-baixa tecnologia & \\
\hline$\overline{M A}$ & Média-Alta tecnologia & $B$ & Baixa tecnologia & EXTindústrias Extrativas \\
\hline & & & & \begin{tabular}{|l|l}
$A G$ & Atividades Agrícolas, Pecuária, etc \\
\end{tabular} \\
\hline
\end{tabular}

Apenas seis setores se integraram às duas trajetórias simultaneamente, ou seja, conseguiram aumentar o valor médio do índice Hirschman-Herfindahl $\left(H H^{\prime}\right)$ e a média dos Valores Unitários de Exportação (VUX) entre os períodos 2009-2012 e 2000-2004. Um setor classificado como Alta tecnologia e Baseado em Ciência, o setor 26 - Informática, Eletrônico e Ópticos; na classe de Média-alta tecnologia e Difusores de Progresso Técnico, o setor 28 - Máquinas e Equipamentos; um setor de Média-baixa tecnologia (setor 19 - Coque, Petróleo e Biocombustíveis), um setor de Baixa tecnologia e Dominado pelos Fornecedores (setor 14 - Vestuário e Acessórios); um setor das Indústrias Extrativas e outro Agrícola (setor 06 Extração de Petróleo e Gás e setor 03 - Pesca e Aquicultura).

Além desses, mais nove setores se integraram apenas à trajetória 2 - Diversificação, com destaque para os setores que compõem a classe de Média-alta e Baixa tecnologias de acordo com a OCDE e a classe Dominado por Fornecedores da classificação Pavitt. Já na trajetória 3 - Diferenciação e Qualidade, apenas mais dois setores se integraram exclusivamente a ela: o setor 24 - Metalurgia, classificado como Média-baixa tecnologia e Intensivas em Escala - processo contínuo e o setor 02 - Produção Florestal.

O resultado foi um pouco diferente quando se observa a variação do valor médio do índice HirschmanHerfindahl $\left(H H^{\prime}\right)$ e a média dos Valores Unitários de Exportação $(V U X)$ entre os períodos 2005-2008 e 2000-2004. Esse período é importante por causa da eclosão da crise financeira que se iniciou no mercado imobiliário dos Estados Unidos em 2008 e alterou a dinâmica da economia e do comércio exterior brasileiros. Três setores estavam integrados à trajetória de diversificação, com índice $H H^{\prime}$ crescente no período 2005-2008 em relação ao período anterior, mas reverteu essa dinâmica após o início da crise: o setor 7 - Extração de Minerais Metálicos, o setor 10 - Produtos Alimentícios e o setor 24 - Metalurgia. No sentido inverso, apenas o setor 26 - Informática, Eletrônicos e Ópticos melhorou sua diversificação no período posterior (2009-2012). A trajetória de diferenciação se mostrou mais estável entre os períodos: apenas o setor 24 - Metalurgia mudou seu desempenho antes e depois da crise, integrando a terceira 
trajetória de desenvolvimento apenas depois do início da crise, no período 2009-2012 em relação ao período 2000-2004.

Portanto, com as condições favoráveis ao comércio exterior brasileiro na década de 2000 e com o crescimento da demanda por nossos produtos minerais e agrícolas, os setores baseados em recursos naturais apresentaram os melhores desempenhos relativos às trajetórias de diversificação e diferenciação, associadas à ampliação da elasticidade-renda da demanda das exportações.

\section{Conclusão}

No longo prazo, as condições para o desenvolvimento dependem da interação entre duas forças motrizes, a difusão do progresso técnico por todos os setores da economia e a expansão da elasticidade-renda da demanda, criando condições para que a produtividade, a diversificação e a diferenciação de produtos aumentem na economia. As exportações de um país podem ser o mecanismo auxiliar nesta dinâmica de desenvolvimento em virtude de todas as conexões que possuem com seu sistema produtivo.

Este artigo focou o comportamento das exportações nas trajetórias de desenvolvimento associadas à segunda força motriz no período de 2000 a 2012. Neste período, as exportações mostraram uma especialização diferente das importações e a composição daquelas não se tornaram mais parecidas com a destas últimas, dado que o Índice de Similaridade entre as duas pautas revelou um valor próximo de 0,50 (entre zero e um) e estável ao longo dos anos.

Em relação à trajetória de diversificação das exportações, os setores que apresentaram os maiores Índices de Diversificação $\left(I D X_{i}\right)$, apesar de heterogêneos quanto à classificação por intensidade tecnológica ou das categorias de Pavitt, tem um fator importante em comum: quatro dos seis principais setores que mais aumentaram sua diversificação são setores baseados, direta ou indiretamente, nos recursos naturais.

Já na terceira trajetória de desenvolvimento, os Índices de Diferenciação e Qualidade ( $\left.I Q X_{i}\right)$ das exportações se mostraram mais específicos aos setores, a se julgar pelo índice $I Q M_{i}$ calculados para as importações. Os setores com maiores $I Q X_{i}$ foram os mesmos para as exportações quanto para as importações. Apesar disso, a ampla desvantagem em termos de qualidade revelada pela razão entre os Valores Unitários sugere que a cesta de exportação brasileira possui qualidade e diferenciação inferiores a dos bens que importa.

Quanto à integração às trajetórias de ampliação da elasticidade-renda apenas seis dos 30 setores analisados se integraram, simultaneamente, às trajetórias de diversificação e diferenciação. E três deles são setores associados aos recursos naturais, incluindo dois setores ligados ao setor petrolífero (Setor 19 Coque, Petróleo e Bicombustíveis e o setor 06 - Extração de Petróleo e Gás). A desagregação do setor 28 - Máquinas e Equipamentos poderá ainda revelar qual a magnitude da influência das máquinas e equipamentos destinados aos setores agrícolas, extrativos e de energia.

A tendência de maior vigor dos setores especializados em recursos naturais nas trajetórias de diversificação e diferenciação indica que os investimentos realizados nesses setores podem ter iniciado um processo coerente com a dinâmica do desenvolvimento econômico. Além disso, elevados valores de $I D X$ e IQX em setores de Alta-média tecnologia sugerem que a indústria nacional manteve uma estrutura complexa entre 2000 e 2012.

Alguns desafios são fundamentais a partir desse ponto: como o conjunto de conhecimentos e know-how dos setores baseados em recursos naturais pode ser difundido para os demais? A desvantagem de qualidade exibida pelas exportações mostrou que o país precisa expandir esse conjunto de capacitações para que se aproxime de uma "fronteira de qualidade" da indústria internacional. A ampliação dessas capacitações e da capacidade de difundir conhecimento e inovação de um setor a outro são elementos 
mais importantes para o desenvolvimento do que a reprodução de uma “cesta adequada” de exportações escolhida a priori.

\section{Bibliografia}

Aoki, M., \& Yoshikawa, H. (2002). Demand saturation-creation and economic growth. Journal of Economic Behavior \& Organization, 48(2), 127-154.

Cavalcante, L. R. (2014). Classificações tecnológicas: uma sistematização. Brasília: Ipea.

Chenery, H. B. (1960). Patterns of industrial growth. The American Economic Review, 50(4), 624-654.

Finger, J. M., \& Kreinin, M. E. (1979). A Measure of 'Export Similarity’ and Its Possible Uses. The Economic Journal, vol. 89, No. 356, 905-912.

Fontagné, L., \& Freudenberg, M. (1997). Intra-industry trade: methodological issues reconsidered (Vol. 97, No. 1). Paris: CEPII.

Fontagné, L., Freudenberg, M., \& Gaulier, G. (2005). Disentangling horizontal and vertical intra-industry trade. Paris: CEPII, 2005-10.

Funke M., Ruhwedel R., (2001) Product variety and economic growth: Empirical evidence for the OECD countries, IMF Staff papers, Vol 48, N², (2001a)

Giles, J.A., \& Williams, C. L. (2000). Export-led growth: a survey of the empirical literature and some non-causality results. Part 1. Journal of International Trade \& Economic Development, 9(3), 261-337.

Grossman, G. M., \& Helpman, E. (1989). Quality ladders in the theory of growth (No. w3099). National Bureau of Economic Research.

Guimarães, E. A. Acumulação e crescimento da firma. Rio de Janeiro: Zahar, 1982.

Hausmann, R. J. Hwang and D. Rodrik. (2006). 'What You Export Matters'. NBER Working paper, 11905.

Hausmann, R., \& Hidalgo, C. A. (2010). Country diversification, product ubiquity, and economic divergence. CID working paper No. 201.

Hausmann, R., Hidalgo, C. A., Bustos, S., Coscia, M., Simoes, A., \& Yildirim, M. A. (2014). The atlas of economic complexity: Mapping paths to prosperity. Mit Press.

Henn, C., Papageorgiou, C., \& Spatafora, N. (2015). Export quality in advanced and developing economies: Evidence from a new dataset (No. ERSD-2015-02). WTO Staff Working Paper.

Hesse, H. (2008). Export diversification and economic growth. Working Paper No. 21. Commission on Growth and Development, World Bank, Washington, DC.

Hidalgo, C. (2015). Why Information Grows: The Evolution of Order, from Atoms to Economies. Basic Books.

Hidalgo, C. A., Klinger, B., Barabási, A. L., \& Hausmann, R. (2007). The product space conditions the development of nations. Science, 317(5837), 482-487.

Hirschman, A. O. (1960). Estratégia do desenvolvimento econômico: The strategy of economic development. 1958. Fundo de cultura.

Hummels, D., \& Klenow, P. J. (2005). The Variety and Quality of a NationГs Exports. The American Economic Review, 95(3). 
Imbs, J., \& Wacziarg, R. (2003). Stages of diversification. American Economic Review, 63-86.

Kaldor, N. (1970). THE CASE FOR REGIONAL POLICIES*. Scottish journal of political economy, 17(3), 337-348.

Krüger, J. J. (2008). Productivity and structural change: a review of the literature. Journal of Economic Surveys, 22(2), 330-363.

Kuznets, S. (1973). Modern economic growth: findings and reflections. The American Economic Review, 247-258.

Lederman, D., \& Maloney, W. (2012). Does what You Export Matter?: In Search of Empirical Guidance for Industrial Policies. World Bank Publications.

Papageorgiou, C., \& Spatafora, M. N. (2012). Economic diversification in LICs: Stylized facts and macroeconomic implications (No. 12-13). International Monetary Fund. ?????

Resende, M., \& Boff, H. (2002). Concentração industrial. Kupfer, D.; Hasenclever, L. Economia Industrial: fundamentos teóricos e práticos no Brasil. Rio de Janeiro: Campus.

Saviotti, P. P., \& Frenken, K. (2008). Export variety and the economic performance of countries. Journal of Evolutionary Economics, 18(2), 201-218.

Saviotti, P. P., \& Metcalfe, J. S. (1984). A theoretical approach to the construction of technological output indicators. Research Policy, 13(3), 141-151.

Saviotti, P. P., \& Pyka, A. (2012). On the co-evolution of innovation and demand: some policy implications. Revue de l'OFCE, (5), 347-388.

Schott, P. K. (2004). Across-product versus within-product specialization in international trade. The Quarterly Journal of Economics, 647-678.

Schumpeter, J. A. (1982). Teoria do desenvolvimento econômico: uma investigação sobre lucros, capital, crédito, juro e o ciclo econômico. São Paulo: Abril Cultural, 125-132.

Syrquin, M. (1988) Patterns of Structural Change. In Chenery, H. E Srinivasan, T. Handbook of Development Economics. Elsevier.

Syrquin, M. (2010). Kuznets and Pasinetti on the study of structural transformation: Never the Twain shall meet? Structural Change and Economic Dynamics, 21(4), 248-257. 